\title{
Epithelial and stromal-specific immune pathway activation in the murine endometrium post-coitum
}

\author{
S L Field, M Cummings and N M Orsi \\ Women's Health Research Group, Leeds Institute of Cancer and Pathology, St James's University Hospital, \\ Leeds LS9 7TF, UK \\ Correspondence should be addressed to N M Orsi; Email: n.m.orsi@leeds.ac.uk
}

\begin{abstract}
The endometrium is a dynamic tissue, demonstrating cyclical growth/remodelling in preparation for implantation. In mice, seminal constituents trigger mechanisms to prepare the endometrium, a process dubbed 'seminal priming' that modifies immune system components and mediates endometrial remodelling in preparation for pregnancy. An array of cytokines has been reported to mediate this interaction, although much of the literature relates to in vitro studies on isolated endometrial epithelial cells. This study measured changes in immune-related gene expression in endometrial epithelial and stromal cells in vivo following natural mating. CD1 mice were naturally mated and sacrificed over the first 4 days post-coitum $(n=3$ each day). Endometrial epithelial and stromal compartments were isolated by laser capture microdissection. Labelled cRNA was generated and hybridised to genome-wide expression microarrays. Pathway analysis identified several immune-related pathways active within epithelial and stromal compartments, in particular relating to cytokine networks, matrix metalloproteinases and prostaglandin synthesis. Cluster analysis demonstrated that the expression of factors involved in immunomodulation/endometrial remodelling differed between the epithelial and stromal compartments in a temporal fashion. This study is the first to examine the disparate responses of the endometrial epithelial and stromal compartments to seminal plasma in vivo in mice, and demonstrates the complexity of the interactions between these two compartments needed to create a permissive environment for implantation.

Reproduction (2015) $150127-138$
\end{abstract}

\section{Introduction}

The endometrium is a dynamic tissue that undergoes cyclical growth and remodelling to varying degrees in different species in preparation for blastocyst implantation. In mice, seminal constituents are thought to trigger the mechanisms preparing the endometrium for implantation in a process dubbed 'seminal priming' (Fig. 1), which can modify immune system components and influence subsequent events in pregnancy (Robertson et al. 2013). The endometrium responds rapidly to seminal fluid exposure by triggering an inflammatory cascade which is soon followed by an influx of leukocytes (Sharkey et al. 2012). Seminal plasma proteins interact with oestrogen $\left(\mathrm{E}_{2}\right)$-primed uterine epithelial cells, resulting in the synthesis of a large array of cytokines and other immunoregulatory factors, such as granulocyte macrophage colony stimulating factor (CSF2), interleukin (IL)6, IL8, monocyte chemoattractant protein (CCL2), matrix metalloproteinases (MMPs) and prostaglandins (PGs) (Sanford et al. 1992, Robertson et al. 1996a). Within hours of this rise in cytokine production, inflammatory cells invade the cervix as the primary site of semen deposition in humans, pigs, rabbits and mice, although in rodents this inflammatory response can be seen throughout the endometrium (Lovell \& Getty 1968, Taylor 1982, Pandya \& Cohen 1985, Claus 1990, McMaster et al. 1992, Rozeboom et al. 1998, Robertson 2005). Myeloid lineage cells such as monocytes/macrophages, dendritic cells and granulocytes of circulatory origin extravasate to accumulate in uterine stromal tissue, with macrophages, neutrophils and other granulocytes in particular further traversing the epithelium to accumulate in the uterine cavity (De et al. 1991, McMaster et al. 1992, Bischof et al. 1994). This initial neutrophil response occurs prior to implantation, with a purported concurrent drop in cytokine profiles and a rise in progesterone $\left(\mathrm{P}_{4}\right)$ (Robertson et al. 1996a). Endometrial leukocytes, however, persist for several days (O'Leary et al. 2004).

Cytokines such as CSF2 (Robertson \& Seamark 1990, Robertson et al. 1996b), leukaemia inhibitory factor (LIF), CCL2 (Wood et al. 1997, 1999, Meter et al. 2005, Boomsma et al. 2009), regulated upon activation normal T cell expressed and secreted (CCL5) (Wood et al. 1997, Altman et al. 1999, Arima et al. 2000) and TGFB have been shown to be expressed in endometrial cell compartments post-coitum, although much of these 


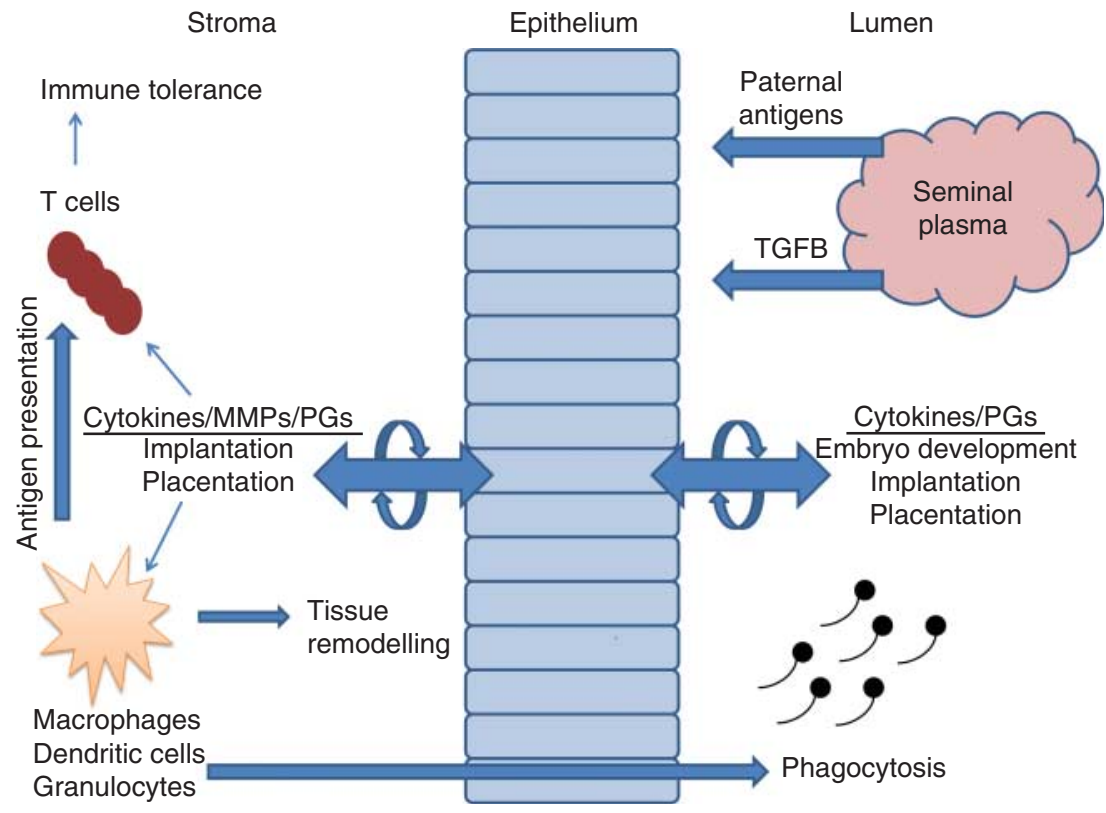

Figure 1 Schematic diagram representing the complex interplay between murine endometrial epithelial and stromal cells following exposure to semen/seminal plasma. Cytokines, matrix metalloproteinases (MMPs) and prostaglandins (PGs), mediate the development of immunotolerance and tissue remodelling in the peri-implantation period to prepare for implantation and subsequent pregnancy. data relate to in vitro models. However, most of the peri-implantation tissue remodelling (both prior to and during decidualisation) appears to be mediated by MMPs (Aplin 1997, Tang et al. 2005). Several MMPs have been implicated, with macrophages being the main source of these proteases, which they produce in response to the prevailing cytokine and PG milieu (Goetzl et al. 1996). However, MMP function is reasonably species-specific: in women, these enzymes are the main mediators of endometrial shedding, whereas this process is largely absent in rodents, where endometrial remodelling merely involves functional regression (Marbaix et al. 1996, Tang et al. 2005).

Alongside endometrial remodelling, a concurrent modification of the maternal immune system occurs in order to promote maternal immunotolerance of the paternal antigens displayed by the implanting blastocyst. Following initial semen deposition in the female reproductive tract, paternal antigens are phagocytosed, processed and presented to maternal $\mathrm{CD}^{+}{ }^{+}$and $\mathrm{CD} 8^{+}$ T cells by antigen presenting cells in the para-aortic lymph nodes (Johansson et al. 2004, Moldenhauer et al. 2009). This induces a functional anergy/hyporesponsiveness in these cells, which promotes conceptus allograft tolerance (Tafuri et al. 1995), in line with a concurrent expansion of the $\mathrm{CD} 4{ }^{+} \mathrm{CD} 25^{+} \mathrm{Foxp}^{+}{ }^{+}$regulatory T cell (Treg) pool (Aluvihare et al. 2004, Shima et al. 2010). The strength of this maternal response depends on seminal plasma composition, particularly paternal antigen content and TGFB concentrations (Robertson et al. 2009). Seminal plasma TGFB in humans and swine is largely accounted for by the TGFB1 isoform (although TGFB2 and 3 are also present), which is secreted in an inactive form requiring activation in the acidic environment of the vagina (Politch et al. 2007). The activation of TGFB1 induces naïve $\mathrm{CD} 4{ }^{+} \mathrm{CD} 25^{-} \mathrm{T}$ cells to differentiate into Foxp3 $^{+}$suppressor/anergic T cells (Chen et al. 2003). The PG component of seminal plasma may also synergise with TGFB in this regard, since $\mathrm{PGE}_{2}$ enhances this inhibitory effect and has been shown to induce a regulatory phenotype in human $\mathrm{CD} 4^{+} \mathrm{CD} 25^{-} \mathrm{T}$ cells in vitro (Baratelli et al. 2005). PG synthesis is also induced by seminal plasma in the porcine uterus, with concurrent angiogenesis extending throughout the preimplantation period (Kaczmarek et al. 2010, 2013).

Although individual immune mediators of the endometrial response to seminal plasma have been identified, few studies have focussed on trying to paint a comprehensive picture of the large number of mediators involved, particularly in terms of characterising the global immunomodulatory responses involved at the level of the transcriptome. Various studies have focussed on profiling gene expression over the course of the implantation window (particularly in women following ovarian stimulation) in order to identify those genes most likely to be involved in the establishment of endometrial receptivity prior to embryo transfer and in relation to the implantation problems allied to endometriosis (Kao et al. 2002, 2003, Riesewijk et al. 2003, Giudice 2004, Burney et al. 2007). To date, however, only one has explored global gene expression in the cervix following stimulation with seminal plasma: Sharkey et al. (2012) performed expression microarray analysis on biopsies of pre- and post-coital human cervix and reported that seminal fluid activated pathways, including the inflammatory response, immune response, immune cell 
trafficking, cell movement and antigen presentation. Within these various pathways, CSF2, IL6 and IL8 mRNA were prominently upregulated post-coitum, as were COX2 and various MMPs, suggesting active leukocyte recruitment and ECM remodelling (Sharkey et al. 2012). Unfortunately, these observations were based only on a single time point in this putatively dynamic process. The aim of the present study was therefore to characterise the endometrial inflammatory response to seminal plasma in vivo in detail throughout the preimplantation period by using a genome-wide screening approach using a murine model. Furthermore, the individual response of the epithelial and stromal cellular compartments to seminal plasma was examined to identify differences in gene expression.

\section{Materials and methods}

\section{Mouse husbandry and mating protocol}

Ethical approval was not required for this study as all work was conducted in compliance with the ethical and legislative framework set out in the Animals (Scientific Procedures) Act, 1986 (UK). Individually housed male (aged 10-12 weeks), and group-housed (10/cage) nulliparous female (aged 6 weeks) CD1 mice were used for these experiments. Animals had ad libitum access to water and the Standard Expanded Beekay diet (B\&K, Grimston, Aldborough, UK) and were kept with a ratio of $14 \mathrm{~h}$ light:12 h darkness, (05:30 on; 19:30 off). Humidity and temperature were maintained at $55-65 \%$ and $21.5 \pm 1{ }^{\circ} \mathrm{C}$ respectively. Whitten effect-synchronised females had their oestrus confirmed by vaginal cytology prior to being naturally mated to CD1 stud males (one female:one male). Five successful copulations were recorded prior to leaving pairs together overnight in order to confirm successful intercourse. Females were then group-housed according to the time of mating, before being sacrificed under Schedule 1 of the Animals (Scientific Procedures) Act, 1986 at 24, 48, 72 and $96 \mathrm{~h}$ after first coitus $\pm 1 \mathrm{~h}$ ( $n=3$ /group). Controls were provided by naturally cycling oestrus and dioestrus females (again assessed on the basis of vaginal cytology, $n=3 /$ group).

\section{Uterine tissue processing and staining}

Within 5 min of culling, the ovaries, uterine horns and vagina were mounted in optimal cutting compound (OCT), frozen in isopentane slush in a liquid nitrogen bath before storage at $-80^{\circ} \mathrm{C}$. Specimens were later sectioned $(12 \mu \mathrm{m})$ at $-16^{\circ} \mathrm{C}$ on a Leica CM3050S Cryostat (Leica Biosystems, UK). Sections were mounted onto Arcturus polyethylene naphthalate (PEN) membrane glass slides (Applied Biosystems) and stained with buffered ethanolic cresyl violet staining solution, as previously described, with minor modifications (Cummings et al. 2011). Sections were briefly rehydrated in a series of ethanol washes $(95,75$ and $50 \%)$ prior to staining with cresyl violet in $75 \%$ ethanol buffered with $20 \mathrm{mM}$ Tris- $\mathrm{HCl}$ pH 8.0 for $40 \mathrm{~s}$. Sections were then dehydrated in a series of ethanol washes $(50,75,95$ and $100 \%$ ). All solutions were prepared using RNAse-free water and molecular-grade absolute ethanol. Slides were stored at $-80^{\circ} \mathrm{C}$ under dessicant prior to laser capture microdissection (LCM).

\section{Laser capture microdissection}

LCM of selected groups of cells was performed on a Zeiss Palm Microbeam UV laser capture microscope, equipped with PALM@Robo Software version 3.2 (Carl Zeiss, Herts, UK). Samples were captured with cut energy set to $51-60 \%$ and laser speed of $20 \mu \mathrm{m} / \mathrm{s}$. Excised areas were captured into adhesive cap tubes (Carl Zeiss), with the average area excised per sample being $3.23 \times 10^{6} \mu \mathrm{m}^{2}$. Both lumenal epithelial and stromal compartments were independently microdissected from the same tissue specimens in order to avoid the risk of RNA cross-contamination (Supplementary Figure 1, see section on supplementary data given at the end of this article).

\section{RNA preparation and microarray analysis}

RNA extraction was performed using Qiagen RNeasy plus micro extraction kits (Qiagen). The extraction protocol was based on the manufacturer's instructions with minor modifications; one extra RPE and $80 \%$ ethanol wash step was incorporated in order to reduce impurity carryover and improve RNA quality. Samples were eluted from the spin column by addition of $14 \mu \mathrm{l}$ RNAse-free water, with $0.5 \mu \mathrm{l}$ RNASecure (Ambion) immediately added to the eluate, which was then heated to $60^{\circ} \mathrm{C}$ for $10 \mathrm{~min}$ to inactivate RNase. Samples were concentrated using a Savant SpeedVac concentrator (Eppendorf, Hamburg, Germany) for 30 min or until dry, then resuspended in $4 \mu \mathrm{l}$ RNAse-free water and stored at $-80{ }^{\circ} \mathrm{C}$ until use. RNA quality and quantity was assessed using Agilent RNA 6000 Nano kit (Agilent, UK) on a 2100 Bioanalyser (Agilent) equipped with 2100 Expert Software using the RNA Eukaryote Total RNA Nano function, and only samples with a RIN value of seven and above were considered suitable for fluorescent cRNA generation.

Fluorescent cRNA was prepared using Agilent One Colour Low Input Quick AMP labelling kit with 10 ng input RNA. Purification of RNA was performed using the RNeasy Mini kit (Qiagen) following the manufacturer's instructions. Replicates were hybridised in different batches to avoid experimental bias. Fluorescent cRNA quality was assessed using a NanoDrop 1000 (Thermo-Scientific UK). Cyanine (Cy3) concentration $(\mathrm{pmol} / \mu \mathrm{l}), \mathrm{RNA} 260 / 280$ ratio and cRNA concentration $(\mathrm{ng} / \mu \mathrm{l})$ were also recorded, and yield and specific activity were calculated for each sample. Samples were hybridised to Agilent SurePrint G3 Mouse GE $8 \times 60 \mathrm{k}$ microarrays as per the manufacturer's instructions. Hybridisation was performed in a hybridisation oven (Agilent) for $17 \mathrm{~h}$ at $65^{\circ} \mathrm{C}$ and a rotation speed of 20 r.p.m. Subsequent washes were completed within $1 \mathrm{~h}$. Slides were scanned immediately to reduce potential variations in signal intensities due to environmental contaminants.

\section{Scanning and feature extraction}

Microarrays were scanned using an Agilent ' $\mathrm{C}$ ' scanner (Agilent), with a scan resolution of $3 \mu \mathrm{m}$. Feature extraction 
was performed using Feature Extraction version 11.0.1.1 (Agilent Technologies). Sample quality was assessed utilising inbuilt quality-control metrics. Eleven of these were applied to the microarray, covering aspects such as alignment, signal intensity and reproducibility, providing a range within which a microarray is considered 'good'. Microarrays falling outside of the manufacturer's 'good' criteria were evaluated for exclusion from the final analysis.

\section{Data analysis}

Data were visualised and analysed using GeneSpring version 12.5 (Agilent Technologies). Data were normalised to the $75 \%$ signal intensity of all probes on the array as recommended by the manufacturer. Samples were examined by the inbuilt principal components analysis (PCA) to identify major outliers. Sample size and desired fold difference were calculated using the Microarray Sample Size Computation tool available at http://bioinformatics.mdanderson.org/microarraysamplesize/. The calculation was based on 55821 entities, with an acceptable false positive rate of $5 \%$, power (percentage of differentially expressed entities likely to be detected by the experiment) of 0.8, and a S.D. of 0.7. Due to the sample size, a fivefold change cut-off was applied to the data. Pathway analysis was performed using the condition averages in order to identify immune pathways active in the murine endometrium. $P$ values were corrected for multiple comparisons using the Benjamini and Hochberg false discovery rate (FDR). The results from the pathway analysis were used in subsequent cluster analyses in IBM SPSS (Version 19). The analysis was performed for epithelium and stroma individually, based on a two-step cluster analysis using Ward linkage. At each iteration, the $\Delta$ coefficient was calculated, with the largest $\Delta$ coefficient defining the number of clusters. Identified mRNA species in each cluster were visualised in GraphPad Prism (Version 6).

\section{Results}

\section{Pathway analysis}

Pathway analysis revealed 217 curated pathways active within the murine uterine tract. Of these pathways, 46 were significant at $P<0.05$, with significance defined by the inbuilt GeneSpring algorithm, which created a composite score of the number of mRNA species matched and the extent of the response of those species (Table 1). Those relating to immune networks were selected in both endometrial epithelial and stromal cell compartments active within the murine endometrium: PG synthesis and regulation $(P<0.001)$, cytokines and inflammatory response $(P<0.001), \operatorname{MMPs}(P=0.01)$, inflammatory response pathway $(P<0.05)$ and the TGFB signalling pathway $(P<0.05)$.

\section{Cluster analysis: epithelial compartment}

Genes encoding cytokine proteins and MMPs highlighted in the pathway analysis were selected for subsequent cluster analysis. These elements fell into eight clusters (Fig. 2). Cluster 1 was defined by peaks in expression on days 1 and 3 post-mating with reduced expression on day 2 (Cxcl3, I/10, I/12a, Mmp9, Mmp20, Mmp25, Tnf). Cluster 2 exhibited a similar pattern of peaks on days 1 and 3, with a less dramatic reduction in expression on day 2 (Bmp4, Egf, II7, I/13, Mmp1a, Mmp3, Mmp16, Mmp28). Cluster 3 generally showed a peak in expression at oestrus and day 2 post-mating with a reduction in expression on day 1 (Ccl5, Csf3, I/1 b, I/15, Inhb1, Mmp11, Mmp14, Mmp23, Thbs). Cluster 4 demonstrated a slight peak at dioestrus and day 1 postmating (Ifng, Mcp1, Mmp2, Mmp19, Tgfb1, Tgfb2, Tgfb3). Cluster 5 showed a dip in expression at oestrus, while remaining relatively constant at other time points (Csf2, Cxcl2, Il2, I/4, II5, I/12b, Itbp1, Mmp10, Mmp12, Mmp13, Mmp21, Mmp24). Cluster 6 exhibited minor peaks on days 2 and 4 post-mating, although many elements showed large variation (Cxcl1, II1a, Lif, Mmp8, Mmp27). Cluster 7 was characterised by peaks at dioestrus, days 1 and 4 post-mating, with a dramatic reduction in expression at days 2 and 3 ( Csf 1 t1 1 Csf 1 t3, Mmp7). Finally, cluster 8 elements exhibited huge variations in expression at each time point, and therefore could not be ascribed to any particular pattern.

\section{Cluster analysis - stromal compartment}

mRNA entities fell into seven clusters (Fig. 3). Cluster 1 comprised three mRNA species (Csf1t1, Csf3, Mmp23) that exhibited a peak at oestrus. Cluster 2 was characterised by a slight increase in expression on day 1 post-mating, with a subsequent decrease on days 2-4 (Bmp4, Csf1t3, Csf2, Cxcl2, Cxcl3, Egf, Ifnb1, II1a, II2, II4, II5, Il6, II7, I/10, II11, II12a, II12b, II13, Mmp1a, Mmp3, Mmp8, Mmp10, Mmp13, Mmp12, Mmp16, Mmp20, Mmp21, Mmp24, Mmp25, Mmp28, Tnf). Cluster 3 comprised only Mmp7, which showed the highest expression at oestrus with the lowest expression on day 3 post-mating. Cluster 4 increased in expression post-mating and remained high on days 2-4 (Ifng, I/15, Mmp2, Mmp19, Tgfb1, Tgfb2, Tgfb3). Cluster 5 peaked on days 1 and 2 post-mating with a subsequent decrease on days 3 and 4 (Ccl5, Inhb1, I/1b, Mcp1, Mmp9, Thbs 1). Cluster 6 peaked on day 1 with a subsequent fall to baseline levels of expression (Mmp11, Mmp14). Cluster 7 was characterised by peaks in expression at dioestrus and day 3 post-mating (Cxcl1, Itbp1, Lif, Mmp27).

\section{Differences in endometrial epithelial and stromal expression}

Many mRNA species displayed differences in expression between endometrial epithelial and stromal cells despite exhibiting similar pathway involvement. The majority 
Table 1 Pathways active in murine endometrial epithelial and stromal cells.

\begin{tabular}{|c|c|c|c|c|}
\hline Pathway & WikiPathways ID & $P$ value & $\begin{array}{c}\text { Number of matched } \\
\text { entities }\end{array}$ & $\begin{array}{c}\text { Number of pathway } \\
\text { entities }\end{array}$ \\
\hline GPCRs, Class A rhodopsin-like & WP189 62834 & 0.00 & 208 & 231 \\
\hline GPCRs, other & WP41 54691 & 0.00 & 150 & 210 \\
\hline GPCRs, other & WP41 62667 & 0.00 & 150 & 210 \\
\hline Cytoplasmic ribosomal proteins & WP163 62833 & 0.00 & 77 & 80 \\
\hline Peptide GPCRs & WP234 41308 & 0.00 & 63 & 70 \\
\hline Metapathway biotransformation & WP1251 41349 & 0.00 & 117 & 143 \\
\hline Monoamine GPCRs & WP570 48232 & 0.00 & 32 & 33 \\
\hline Monoamine GPCRs & WP570 60231 & 0.00 & 32 & 33 \\
\hline Calcium regulation in the cardiac cell & WP553 47774 & 0.00 & 120 & 150 \\
\hline Striated muscle contraction & WP216 41273 & 0.00 & 40 & 45 \\
\hline Complement and coagulation cascades & WP449 41301 & 0.00 & 53 & 62 \\
\hline Prostaglandin synthesis and regulation & WP374 41394 & 0.00 & 29 & 31 \\
\hline Small Ligand GPCRs & WP353 41279 & 0.00 & 18 & 18 \\
\hline Selenium & WP1272 58514 & 0.00 & 22 & 31 \\
\hline Cytokines and inflammatory response (BioCarta) & WP222 53571 & 0.00 & 26 & 30 \\
\hline Selenium & WP1272 59028 & 0.00 & 21 & 31 \\
\hline Complement activation, classical pathway & WP200 47967 & 0.00 & 16 & 17 \\
\hline Cytochrome P450 & WP1274 48227 & 0.00 & 35 & 40 \\
\hline Myometrial relaxation and contraction pathways & WP385 47969 & 0.00 & 120 & 157 \\
\hline Blood clotting cascade & WP460 62696 & 0.00 & 19 & 20 \\
\hline Glucocorticoid and mineralcorticoid metabolism & WP495 62838 & 0.00 & 13 & 13 \\
\hline SIDS susceptibility pathways & WP1266 58254 & 0.00 & 49 & 61 \\
\hline SIDS susceptibility pathways & WP1266_58281 & 0.00 & 49 & 61 \\
\hline GPCRs, Class B secretin-like & WP456 41317 & 0.01 & 20 & 22 \\
\hline Nuclear receptors in lipid metabolism and toxicity & WP431 47744 & 0.01 & 26 & 30 \\
\hline Glucuronidation & WP1241 59029 & 0.01 & 11 & 18 \\
\hline Irinotecan pathway & WP475 48258 & 0.01 & 11 & 11 \\
\hline Matrix metalloproteinases & WP441 41300 & 0.01 & 25 & 29 \\
\hline Macrophage markers & WP2271 53132 & 0.01 & 10 & 10 \\
\hline $\begin{array}{l}\text { XPodNet - protein-protein interactions in the podocyte } \\
\text { expanded by STRING }\end{array}$ & WP2309 58142 & 0.01 & 573 & 836 \\
\hline $\begin{array}{l}\text { XPodNet - protein-protein interactions in the podocyte } \\
\text { expanded by STRING }\end{array}$ & WP2309 58143 & 0.01 & 573 & 836 \\
\hline Oxidative stress & WP412 41381 & 0.02 & 24 & 29 \\
\hline GPCRs, Class C metabotropic glutamate, pheromone & WP327 41361 & 0.02 & 14 & 15 \\
\hline Folic acid network & WP1273 48256 & 0.02 & 20 & 27 \\
\hline Inflammatory response athway & WP458 57463 & 0.03 & 25 & 30 \\
\hline TGF $\beta$ signalling pathway & WP113 41270 & 0.03 & 41 & 52 \\
\hline Metapathway biotransformation & WP125159060 & 0.03 & 22 & 143 \\
\hline Hedgehog signalling pathway & WP116 41332 & 0.03 & 19 & 22 \\
\hline Folic acid network & WP1273 60224 & 0.03 & 19 & 27 \\
\hline Glycolysis and gluconeogenesis & WP157 43573 & 0.03 & 38 & 48 \\
\hline Endochondral ossification & WP1270 41292 & 0.03 & 48 & 62 \\
\hline Serotonin and anxiety-related events & WP2140 58159 & 0.03 & 12 & 13 \\
\hline Glycolysis and gluconeogenesis & WP157 51735 & 0.04 & 39 & 50 \\
\hline ESC pluripotency pathways & WP339 42897 & 0.04 & 81 & 111 \\
\hline Retinol metabolism & WP125951364 & 0.04 & 31 & 39 \\
\hline $\mathrm{E}_{2}$ metabolism & WP1264 48250 & 0.04 & 11 & 13 \\
\hline
\end{tabular}

showed greater relative expression profiles in stromal cells as compared to epithelial cells, with the exception of Mmp7 and elements of the PG pathway, which were consistently more highly expressed in epithelial cells.

CSFs varied in expression in each cell type, with notable differences in both transcript variants of Csf1 (Fig. 4). This mRNA peaked on days 1 and 4 post-mating in the epithelium, while stromal expression remained relatively constant. Csf2 showed a minor peak in expression on day 1 post-mating in both epithelium and stroma, with epithelial expression peaking on day 4 while stromal expression slowly declined. Of the CSFs, Csf3 showed the greatest difference in expression between epithelium and stroma, with a dramatic drop in epithelial expression on day 1 followed by a peak on day 2 post-mating.

Transforming growth factors (TGFs) were consistently more highly expressed in stroma than in epithelium (Fig. 5). Tgfb1 exhibited a divergence between stromal and epithelial expression on day 1 post-mating, with stromal expression increasing while epithelial expression decreased. Tgfb2 showed a similar divergence on day 2 post-mating. Interferons (Ifnb and Ifng) were both detected in murine endometrium, with a higher relative expression noted in stroma (Fig. 6). There was one exception to this pattern: Ifnb epithelial 

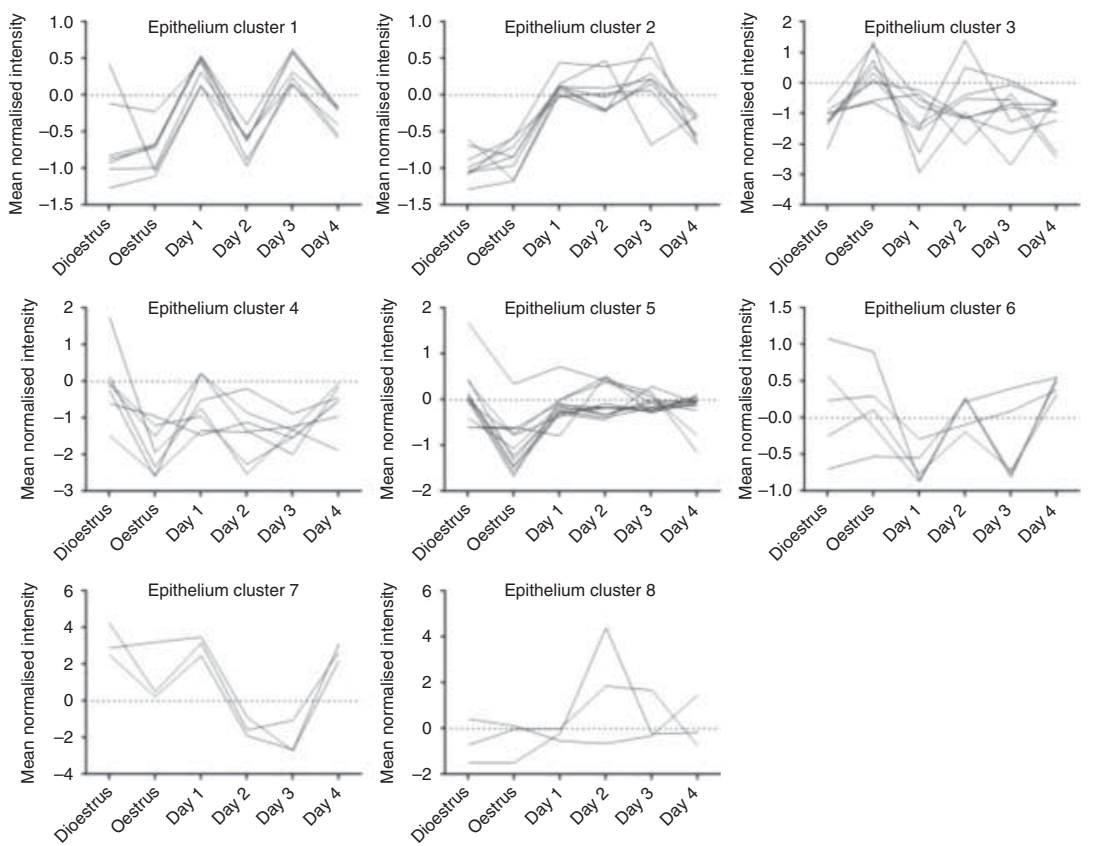

Figure 2 Cluster analysis of mRNA encoding cytokines and MMPs in murine endometrial epithelial cells. Clusters were identified by a twostep cluster analysis using Ward linkage. At each iteration, the $\Delta$ coefficient was calculated, with the largest $\Delta$ coefficient defining the number of clusters. Cluster membership: cluster $1-\mathrm{CxCl} 3$, II10, Il12a, Mmp9, Mmp20, Mmp25, Tnf; cluster 2 - Bmp4, Egf, II7, II13, Mmp1a, Mmp3, Mmp16, Mmp28; cluster 3 - Ccl5, Csf3, I/1b, I/15, Inhb1, Mmp11, Mmp14, Mmp23, Thbs; cluster 4 - Ifng, Mcp1, Mmp2, Mmp19, Tgfb1, Tgfb2, Tgfb3; cluster 5 - Csf2, Cxcl2, II2, II4, II5, II12b, Itbp1, Mmp10, Mmp12, Mmp13, Mmp21, Mmp24; cluster 6-Cxcl1, II1a, Lif, Mmp8, Mmp27; cluster 7 - Csf1t1, Csf1t3, Mmp7; cluster 8 - Ifnb, II6, II11. expression peaked above stromal expression on day 2 post-coitum. Differences were noted in other inflammatory cytokines too: Tnf, Lif and Ccl5 were all expressed in endometrial stroma at relatively higher levels than in epithelium, with the exception of $\operatorname{Tnf}$ and Lif on day 4 (Fig. 7). Ccl5 expression patterns were similar in both compartments post-coitum.

Elements of the PG pathway were also implicated: PG synthases were detected in both endometrial epithelium and stroma (Fig. 8). Ptgs1 (Cox1) demonstrated a dramatic increase in epithelial expression, which was relatively higher than stromal expression on day 2 postmating; this was sustained until a day 4 drop. Ptgs 2 (Cox2) peaked in the epithelium on day 2 post-coitum. The PG E receptors Ptger1, Ptger2, Ptger3 and Ptger4 exhibited differences in expression between endometrial epithelial and stromal cells. Both Ptger1 and Ptger3 were more highly expressed in stroma than in epithelium.
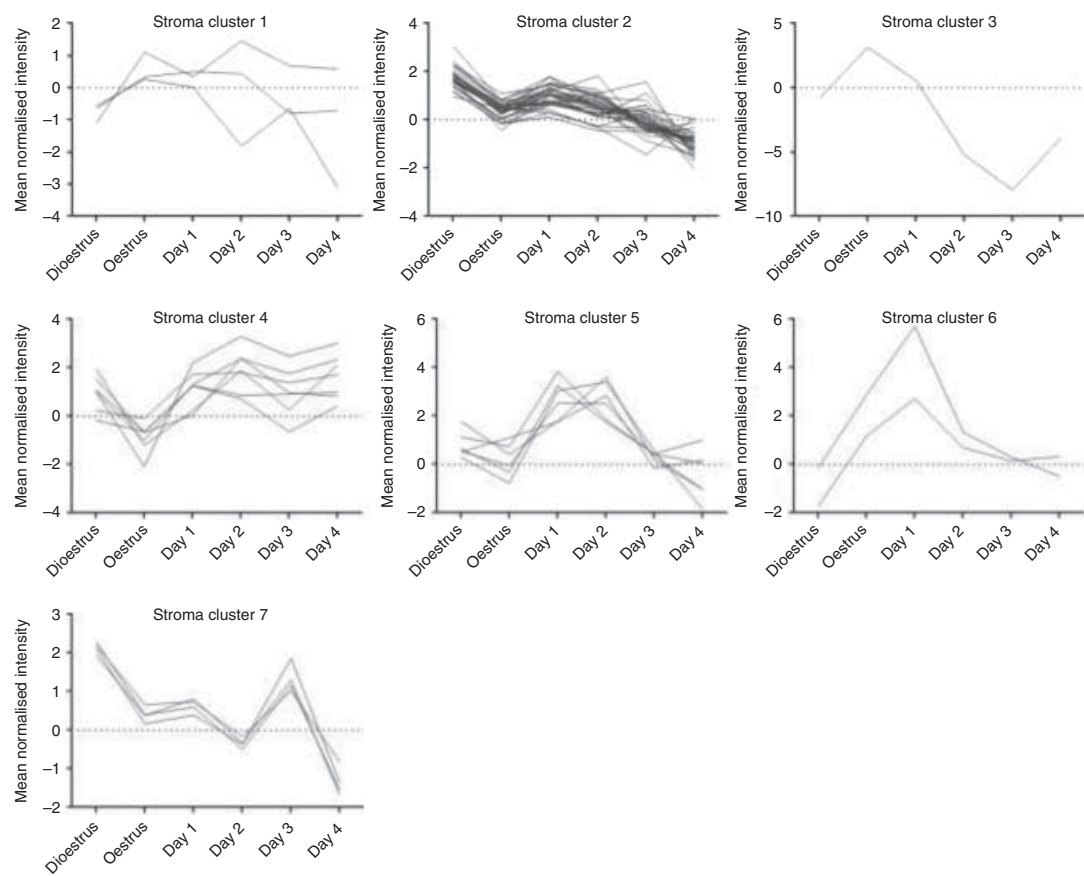

Reproduction (2015) 150 127-138
Figure 3 Cluster analysis of mRNA encoding cytokines and MMPs in murine endometrial stromal cells. Clusters were identified by a two-step cluster analysis using Ward linkage. At each iteration, the $\Delta$ coefficient was calculated, with the largest $\Delta$ coefficient defining the number of clusters. Cluster membership: cluster $1-C s f 1 t 1, C s f 3$, Mmp23; cluster 2 - Bmp4, Csf1t3, Csf2, Cxcl2, CxCl3, Egf, Ifnb1, II1a, II2, II4, II5, II6, II7, II10, II11, Il12a, Il12b, Il13, Mmp1a, Mmp3, Mmp8, Mmp10, Mmp13, Mmp12, Mmp16, Mmp20, Mmp21, Mmp24, Mmp25, Mmp28, Tnf; cluster 3 - Mmp7; cluster 4 - Ifng, I/15, Mmp2, Mmp19, Tgfb1, Tgfb2, Tgfb3; cluster 5 - Ccl5, Inhb1, Il1b, Mcp1, Mmp9, Thbs1; cluster 6 - Mmp11, Mmp14; cluster 7 Cxcl1, Itbp1, Lif, Mmp27. 


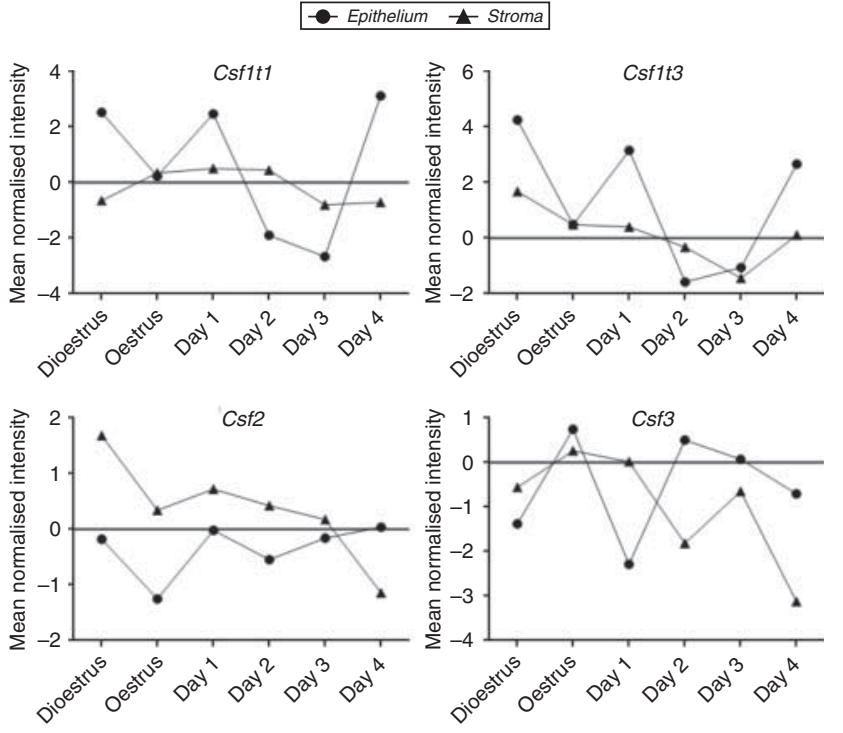

Figure 4 Relative CSF mRNA expression in murine endometrial epithelial and stromal cells post coitum. Csf1 (both transcript variants) varied little in the epithelium, while peaking on days 1 and 4 in the stroma. Csf2 exhibited higher stromal expression at all time points except day 4. Csf3 exhibited the most variation across cell type and time point.

Ptger 1 showed an increase in stromal expression with a concurrent decrease in epithelial expression on day 2 post-mating. Ptger2 and Ptger 4 were consistently more highly expressed in epithelium than in stroma. Ptger2 peaked on days 1 and 4 post-mating, while Ptger 4 peaked on day 3 (Fig. 7).

\section{Discussion}

This study characterised the murine endometrial epithelial and stromal responses to seminal plasma in the development of maternal immunotolerance to the foetal allograft. Various mediators of this response have been identified. Chief amongst these, CSF2 is secreted into the uterine lumen within hours of coitus (Robertson \& Seamark 1990, Robertson et al. 1996b). This ties in well with the present findings, where Csf2 expression was noted to rise markedly between oestrus and day 1 in both epithelial and stromal compartments. Relative stromal expression exceeded that of the epithelium except on day 4 , suggesting that stroma may be the principal source of CSF2. This challenges the conventional epitheliumcentric view borne from studies based on trypsinised cell cultures or antibody-based panning techniques that may alter epithelial cell phenotype and response (Robertson \& Seamark 1990, Robertson et al. 1992,1996b). Moreover, the stromal role is often overlooked in the design of such investigations. Csf2 mRNA extracted from entire murine uteri post- coitum has been shown to be upregulated across days 1 and 2 (Robertson et al. 1996a), in contrast to the day 2 decline reported here. This may reflect differences in mouse strain or use of the entire organ mRNA pool rather than the more selective approach used herein. Csf2 was raised on day 1 postmating in both epithelium and stroma, pointing to its likely involvement in the endometrial response to seminal plasma. Epithelial Csf2 expression was highest on day 4, suggesting its involvement in endometrial receptivity to the implanting blastocyst. Indeed, CSF2 recruits leukocytes to the endometrium to facilitate implantation, with dendritic cells, regulatory $\mathrm{T}$ cells and natural killer cells coordinating trophoblast invasion (Bulmer et al. 1991, Gonzalez et al. 2012, Hatta et al. 2012, Male et al. 2012, Chaouat 2013, Erlebacher 2013, Fu et al. 2013, Hemberger 2013). Its importance in placentation is highlighted by a study of null mice that showed that absence of CSF2 was associated with late pregnancy loss and delayed foetal growth (Seymour et al. 1997). CSF1 is a weak chemotactic agent, recruiting macrophages to the epithelium (Wood et al. 1997), such that its protein levels correlate with macrophage numbers (Pollard et al. 1987). In the present study, epithelial Csf1 expression peaked on days 1 and 4, suggesting two waves of macrophage recruitment. Conceivably, the day 1 wave could be accounted for by the role of macrophages as antigen-presenting cells in the induction of maternal immunotolerance alongside their phagocytic clearance of seminal components within the uterine lumen (Olive et al. 1987), while on day 4 , they may participate in tissue remodelling and increasing epithelial cell adhesiveness in preparation for implantation (Lee et al. 2011).

Epithelial cluster 1 transcripts $(\mathrm{CxCl} 3, \mathrm{I} / 10, \mathrm{I} / 12 \mathrm{a}$, Mmp9, Mmp20, Mmp25, Tnf) peaked on days 1 and 4

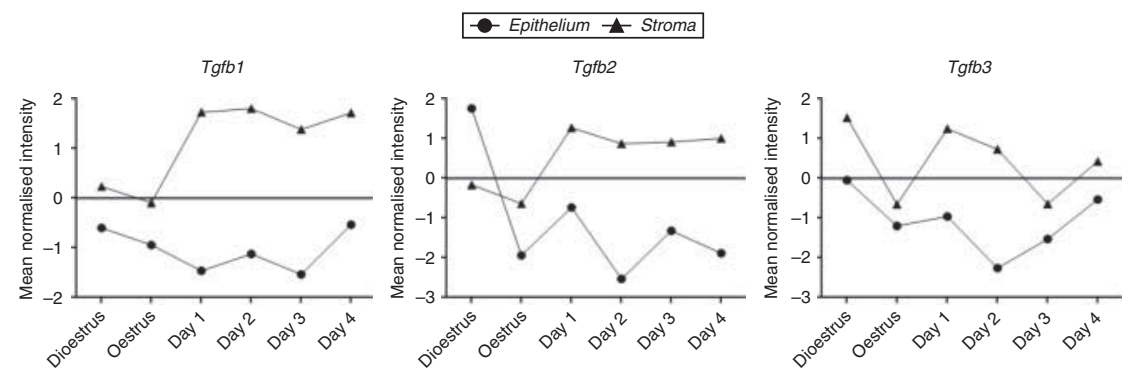

Figure 5 Murine endometrial cell relative TGFB mRNA expression in the pre-implantation period. All Tgfb isoforms were consistently more highly expressed in the stromal compartment post-mating. With the exception of Tgfb1, which demonstrated a reduction in stromal compartment expression, all isoforms exhibited a rise in expression in day 1 post-mating. 


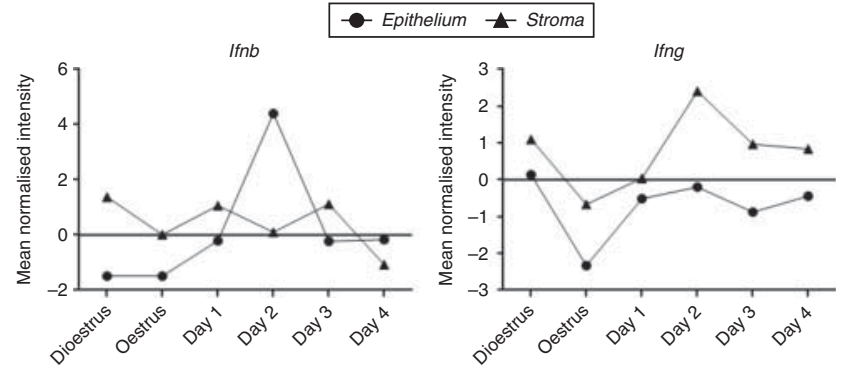

Figure 6 Relative Ifnb and Ifng expression in murine endometrial cell compartments post-mating. Ifnb exhibited a sharp peak in expression on day 2 post-mating in the stromal compartment, while Ifng showed a peak at this time point in the epithelium.

post-mating. TNFA is key to the acute inflammatory response (Warren et al. 1988), accounting for its early expression. CXCL3 controls monocyte adhesion and migration (Smith et al. 2005), thus likely mediating macrophage recruitment. Although CXCL3 is induced by IL13 (Ooi et al. 2012), their transcripts did not cluster, potentially due to functional redundancy (see below). MMPs also featured prominently in the initial epithelial response to seminal plasma, suggesting some degree of early remodelling and/or neoangiogenic signalling to stroma in preparation for implantation (Rundhaug 2005).

Expression of epithelial clusters 3 (Ccl5, Csf3, II1b, II15, Inhb1, Mmp11, Mmp14, Mmp23, Thbs1) and 6 (CxCl1, Il1a, Lif, Mmp8, Mmp27) was downregulated on day 1 post-mating. This is surprising because CCl5, Csf3, CxCl1 and I/15 are leukocyte chemotactic/differentiation agents whose levels might be expected to parallel leukocyte activity post coitum (Schall et al. 1990, Bleul et al. 1996, Wood et al. 1997, Ashkar et al. 2003, Kryczek et al. 2005). Instead, Ccl5 and I/15 expression rose in stroma, suggesting that this compartment may be their principal source. This may also reflect a degree of functional redundancy, a phenomenon partly due to cytokine receptors sharing a common subunit specific to a family of cytokines. For example, IL2 deficiency can be compensated by other cytokines in its family (IL4, IL7, IL9, IL15, IL21) that signal through its receptor by binding to the common $\gamma$-chain (Lin et al. 1995, Ozaki \& Leonard 2002). This family of ILs falls into clusters 3 and 5, whose expression either fails to increase above baseline or is downregulated post-mating, with the exception of $I / 7$ (cluster 2), which peaked on days 1-3. It is tempting to speculate that $1 / 7$ performs an overarching function on behalf of its family, rendering the others functionally redundant. Alternatively, other mediators may operate as selective suppressors of $1 / 4$, $1 / 9$, $/ / 15$ and $/ / 21$ expression although this cannot be determined from our data. The apparent day 1 downregulation of $I / 1 a$ and $I / 1 b$ may be due to the fact that the inflammatory response may peak and fall prior to day 1 sampling. This is conceivable because cytokine expression increases within hours (e.g. $<3 \mathrm{~h}$ for $\| 11 \mathrm{~b}$ in human endometrial epithelial cells in vitro; Gutsche et al. (2003)). It is however more probable that the inflammatory response itself is modified to induce maternal tolerance to paternal antigens without necessarily involving the stereotypical acute phase cytokine cascade.
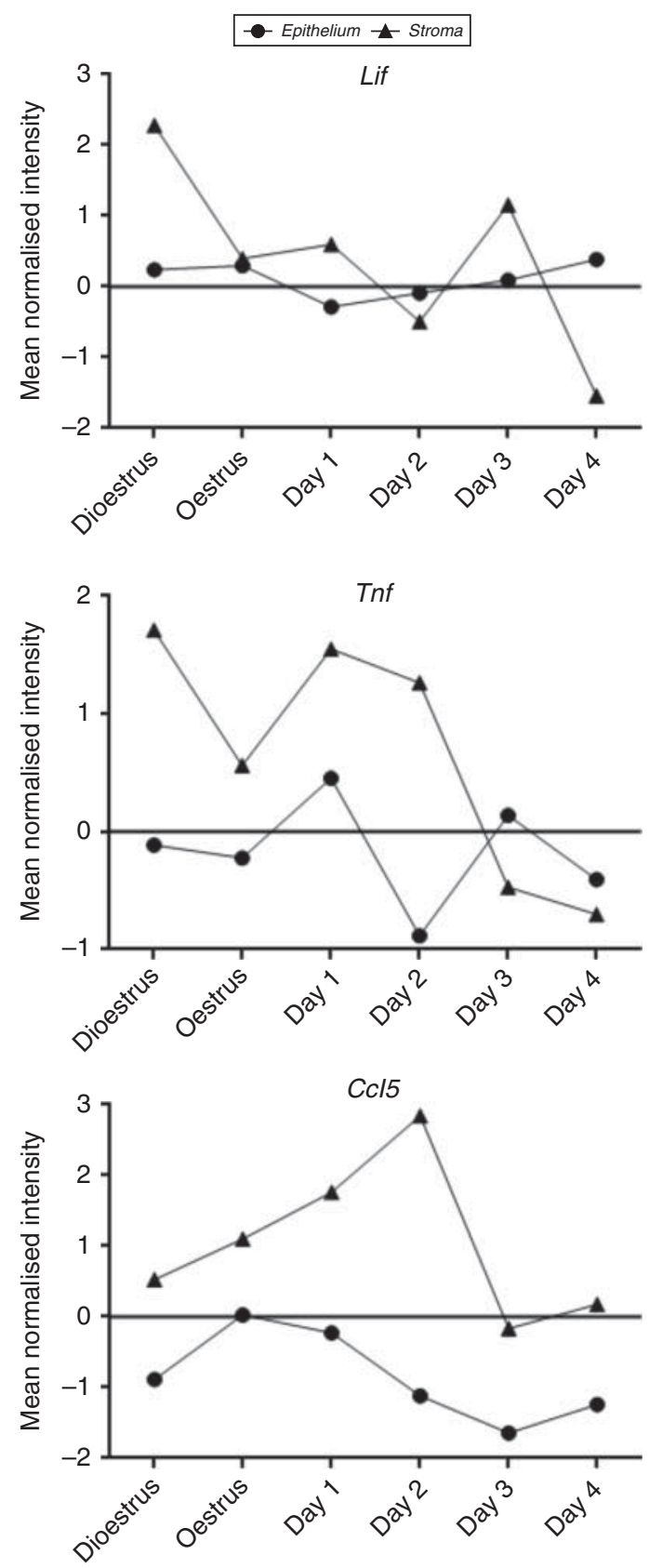

Figure 7 Relative expression (mean normalised intensity) of Lif, Tnf and Ccl5 in murine endometrial epithelial and stromal compartments. Lif expression remained relatively constant except at day 4, while Tnf expression profiles were similar in both compartments although with higher expression in the stromal compartment at all days except day 4. CCl5 expression was consistently more highly expressed in the stromal compartment. 

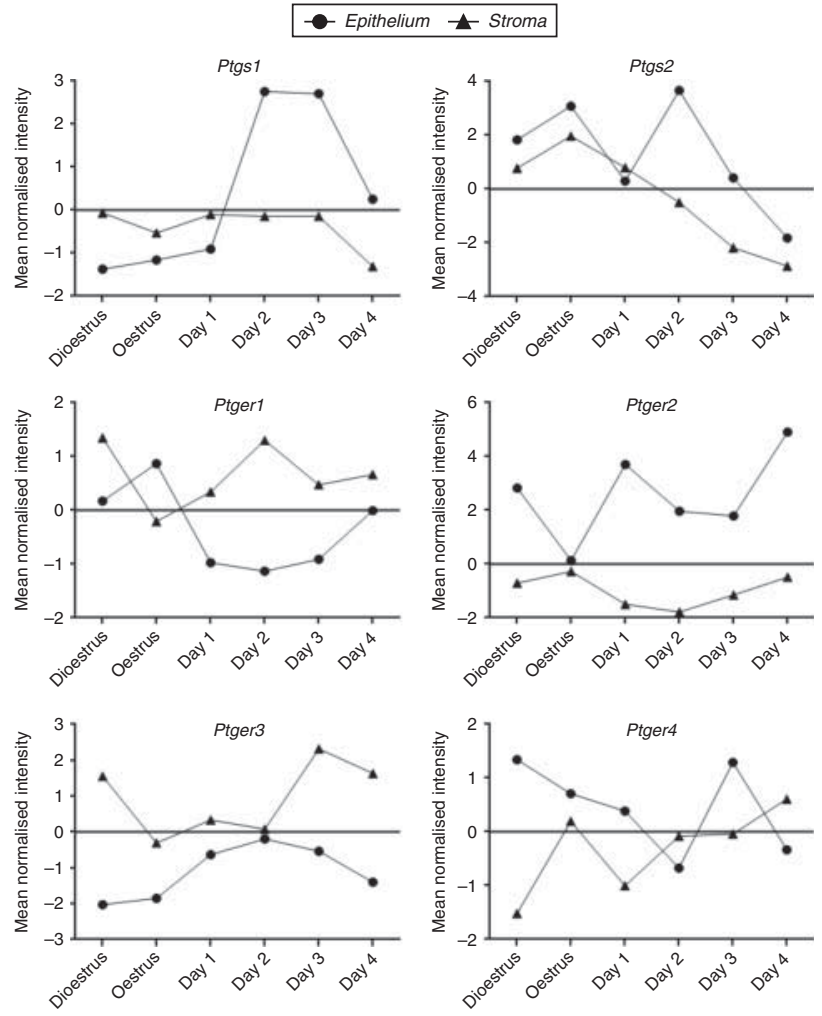

Figure 8 Murine endometrial expression of prostaglandin pathway elements during the pre-implantation period. Synthases Ptgs1 and Ptgs2 peaked on day 2 in the epithelium with a subsequent decline to day 4. Receptor expression varied, with Ptger 1 and Ptger3 having relatively higher stromal expression, while Ptger2 and Ptger4 followed the opposite pattern.

PG-endoperoxide synthases (PTGSs; cyclooxygenases) shape the implantation-related PG response and influence immune function, angiogenesis and tissue remodelling (Salleh 2014). We found that post-coitum Ptgs1 and Ptgs2 expression localised to the epithelium, a profile reflected by their protein localisation in both post-mating rats and cycling human uteri (Yang et al. 2002). PG receptor Ptger1 and Ptger3 expression rose in stroma in parallel to epithelial Ptgs2, suggesting paracrine interactions between the two compartments. Cluster 2 (Bmp4, Egf, II7, II13, Mmp1a, Mmp3, Mmp16, Mmp28) epithelial expression rose post-mating and was sustained until day 4. EGF and IL7 are functionally similar in inducing immune effector cell proliferation and differentiation (Niu \& Qin 2013) while IL13 modulates human monocyte/B cell function and downregulates/induces MMPs based on the physiological setting (Wadsworth et al. 2010, Bailey et al. 2012, Firszt et al. 2013). Their sustained mRNA expression supports their role in inducing immunotolerance and stromal remodelling.

As regards the stromal response, cluster $5(\mathrm{Ccl} 5, \mathrm{I} / 1 \mathrm{~b}$, Inhb1, Mcp1, Mmp9, Thbs1) was of most interest; expression peaked on days 1 and 2 post-mating and fell on days 3 and 4 . In contrast to the epithelial response, the increase in $/ / 1 b$ expression suggests that its stromal function may relate to its role in governing cell proliferation/differentiation, inducing PTGS2 expression and regulating MMPs (Rossi et al. 2005), in agreement with the rise in day 2 stromal Ptgs 2 expression. IL1B also likely influences the steroid hormone microenvironment through its suppression of steroid sulphatase activity (Matsuoka et al. 2002), thereby reducing stromal oestrogenic effects so as to create an environment favourable for nidation. The remaining cluster 5 members mediate leukocyte recruitment and extracellular remodelling in preparation for implantation, as discussed earlier.

Cluster 4 (Ifng, II15, Mmp2, Mmp19, Tgfb1, Tgfb2, Tgfb3) stromal gene expression levels rose on day 1 and remained high thereafter, in contrast to the epithelium. While these agents regulate epithelial proliferation/ remodelling in the menstrual cycle (Gold et al. 1994, Godkin \& Dore 1998), this apparent discrepancy may reflect a paracrine stroma:epithelial relationship, such that bidirectional communication is essential to coordinate the preparatory changes for implantation. TGFB1 can inhibit proliferation and induce PTGS2/prolactin expression in human endometrial stromal cells in vitro (Chang et al. 2008), pointing to a role in tissue remodelling in preparation for decidualisation, as supported by the present data. MMP2 and 9 cleave latent TGFB into its active form (Yu \& Stamenkovic 2000), accounting for our observation that Mmp2 clusters with all TGFB isoforms in both epithelium and stroma. As such, MMP:TGFB signalling pathway interactions may participate in creating the immunopermissive environment of implantation. In contrast with our findings, a murine study showed TGFB2 expression to be confined to the epithelium during the preimplantation period (Das et al. 1992), which may reflect posttranscriptional processes. Ifng and Tgfb isoform transcript clustering in stroma was expected given that these cytokines display antagonistic relationships (Eickelberg et al. 2001, Higashi et al. 2003, Yu et al. 2006). In murine and human endometrial epithelium, IFNG has a strong inhibitory effect on TGFB via TGFB type II receptor (Tgfbr2) downregulation (Yu et al. 2006). Ifng is unlikely to perform a similar role in stroma since Tgfbr2 was upregulated on day 1 post-mating (data not shown). Instead, the parallel reduction in Tgfbr2 expression in the epithelium points to paracrine stromal:epithelial interactions. A likely endometrial role for both these agents revolves around regulating $T$ cell function: IFNG induces $\mathrm{T}$ cell apoptosis/inhibits their proliferation, while TGFB promotes naïve $T$ cell differentiation into Tregs (Chen 2011). IFNG also has anti-proliferative effects on human endometrial epithelial cells in vitro (Tabibzadeh et al. 1988) and an inhibitory effect on stromal VEGF production (Kawano et al. 2000), which is at odds with post-coital endometrial events occurring in vivo. 
To our knowledge, this is the first study to characterise comprehensively the post-coitum physiological changes in endometrial epithelial and stromal gene expression. Immune pathways were most affected and exhibited dynamic, quantitatively and chronologically distinct compartment-specific changes. Since the expression and bioactivity of many of the mediators involved are subject to both post-transcriptional and post-translational regulation, future studies should focus analyses at the protein level to draw more functional interpretations. Moreover, the cluster analysis used herein (and in other studies) is based on pre-defined pathways intrinsic to microarray analytical software, which may be overly prescriptive and prevent the identification of novel, broader network interactions (e.g. cytokine/eicosanoid/hormone interactions in inflammatory networks). This calls for new analytical and modelling strategies to account for these phenomena.

\section{Supplementary data}

This is linked to the online version of the paper at http://dx.doi. org/10.1530/REP-15-0087.

\section{Declaration of interest}

The authors declare that there is no conflict of interest that could be perceived as prejudicing the impartiality of the research reported.

\section{Funding}

The authors are greatly indebted for generous funding from The Infertility Research Trust.

\section{References}

Altman GB, Gown AM, Luchtel DL \& Baker C 1999 RANTES production by cultured primate endometrial epithelial cells. American Journal of Reproductive Immunology 42 168-174. (doi:10.1111/j.1600-0897. 1999.tb00481.x)

Aluvihare VR, Kallikourdis M \& Betz AG 2004 Regulatory T cells mediate maternal tolerance to the fetus. Nature Immunology 5 266-271. (doi:10. 1038/ni1037)

Aplin JD 1997 Adhesion molecules in implantation. Reviews of Reproduction 2 84-93. (doi:10.1530/ror.0.0020084)

Arima K, Nasu K, Narahara H, Fujisawa K, Matsui N \& Miyakawa I 2000 Effects of lipopolysaccharide and cytokines on production of RANTES by cultured human endometrial stromal cells. Molecular Human Reproduction 6 246-251. (doi:10.1093/molehr/6.3.246)

Ashkar AA, Black GP, Wei Q, He H, Liang L, Head JR \& Croy BA 2003 Assessment of requirements for IL-15 and IFN regulatory factors in uterine NK cell differentiation and function during pregnancy. Journal of Immunology 171 2937-2944. (doi:10.4049/jimmunol.171.6.2937)

Bailey JR, Bland PW, Tarlton JF, Peters I, Moorghen M, Sylvester PA, Probert CS \& Whiting CV 2012 IL-13 promotes collagen accumulation in Crohn's disease fibrosis by down-regulation of fibroblast MMP synthesis: a role for innate lymphoid cells? PLOS ONE 7 e52332. (doi:10.1371/ journal.pone.0052332)

Baratelli F, Lin Y, Zhu L, Yang SC, Heuze-Vourc'h N, Zeng G, Reckamp K, Dohadwala M, Sharma S \& Dubinett SM 2005 Prostaglandin $E_{2}$ induces
FOXP3 gene expression and T regulatory cell function in human $\mathrm{CD}^{+}{ }^{+} \mathrm{T}$ cells. Journal of Immunology 175 1483-1490. (doi:10.4049/jimmunol. 175.3.1483)

Bischof RJ, Lee CS, Brandon MR \& Meeusen E 1994 Inflammatory response in the pig uterus induced by seminal plasma. Journal of Reproductive Immunology 26 131-146. (doi:10.1016/01650378(94)90036-1)

Bleul CC, Fuhlbrigge RC, Casasnovas JM, Aiuti A \& Springer TA 1996 A highly efficacious lymphocyte chemoattractant, stromal cell-derived factor 1 (SDF-1). Journal of Experimental Medicine 184 1101-1109. (doi:10.1084/jem.184.3.1101)

Boomsma CM, Kavelaars A, Eijkemans MJ, Lentjes EG, Fauser BC, Heijnen CJ \& Macklon NS 2009 Endometrial secretion analysis identifies a cytokine profile predictive of pregnancy in IVF. Human Reproduction 24 1427-1435. (doi:10.1093/humrep/dep011)

Bulmer JN, Morrison L, Longfellow M, Ritson A \& Pace D 1991 Granulated lymphocytes in human endometrium: histochemical and immunohistochemical studies. Human Reproduction 6 791-798.

Burney RO, Talbi S, Hamilton AE, Vo KC, Nyegaard M, Nezhat CR, Lessey BA \& Giudice LC 2007 Gene expression analysis of endometrium reveals progesterone resistance and candidate susceptibility genes in women with endometriosis. Endocrinology 148 3814-3826. (doi:10. 1210/en.2006-1692)

Chang HJ, Lee JH, Hwang KJ, Kim MR, Chang KH, Park DW \& Min CK 2008 Transforming growth factor (TGF)- $\beta 1$-induced human endometrial stromal cell decidualization through extracellular signal-regulated kinase and Smad activation in vitro: peroxisome proliferator-activated receptor $\gamma$ acts as a negative regulator of TGF- $\beta 1$. Fertility and Sterility 90 1357-1365. (doi:10.1016/j.fertnstert.2007.09.010)

Chaouat G 2013 Inflammation, NK cells and implantation: friend and foe (the good, the bad and the ugly?): replacing placental viviparity in an evolutionary perspective. Journal of Reproductive Immunology 97 2-13. (doi:10.1016/j.jri.2012.10.009)

Chen W 2011 IDO: more than an enzyme. Nature Immunology 12 809-811. (doi:10.1038/ni.2088)

Chen W, Jin W, Hardegen N, Lei KJ, Li L, Marinos N, McGrady G \& Wahl SM 2003 Conversion of peripheral CD4 ${ }^{+} \mathrm{CD}_{2} 5^{-}$naive T cells to $\mathrm{CD} 4{ }^{+} \mathrm{CD} 25^{+}$regulatory $\mathrm{T}$ cells by TGF- $\beta$ induction of transcription factor Foxp3. Journal of Experimental Medicine 198 1875-1886. (doi:10.1084/jem.20030152)

Claus R 1990 Physiological role of seminal components in the reproductive tract of the female pig. Journal of Reproduction and Fertility. Supplement 40 117-131.

Cummings M, McGinley CV, Wilkinson N, Field SL, Duffy SR \& Orsi NM 2011 A robust RNA integrity-preserving staining protocol for laser capture microdissection of endometrial cancer tissue. Analytical Biochemistry 416 123-125. (doi:10.1016/j.ab.2011.05.009)

Das SK, Flanders KC, Andrews GK \& Dey SK 1992 Expression of transforming growth factor- $\beta$ isoforms $(\beta 2$ and $\beta 3)$ in the mouse uterus: analysis of the periimplantation period and effects of ovarian steroids. Endocrinology 130 3459-3466.

De M, Choudhuri R \& Wood GW 1991 Determination of the number and distribution of macrophages, lymphocytes, and granulocytes in the mouse uterus from mating through implantation. Journal of Leukocyte Biology 50 252-262.

Eickelberg O, Pansky A, Koehler E, Bihl M, Tamm M, Hildebrand P, Perruchoud AP, Kashgarian M \& Roth M 2001 Molecular mechanisms of TGF- $(\beta)$ antagonism by interferon $(\gamma)$ and cyclosporine $A$ in lung fibroblasts. FASEB Journal 15 797-806. (doi:10.1096/fj.00-0233com)

Erlebacher A 2013 Immunology of the maternal-fetal interface. Annual Review of Immunology 31 387-411. (doi:10.1146/annurev-immunol032712-100003)

Firszt R, Francisco D, Church TD, Thomas JM, Ingram JL \& Kraft M 2013 Interleukin-13 induces collagen type-1 expression through matrix metalloproteinase- 2 and transforming growth factor- $\beta 1$ in airway fibroblasts in asthma. European Respiratory Journal 43 464-473. (doi:10.1183/09031936.00068712)

Fu B, Li X, Sun R, Tong X, Ling B, Tian Z \& Wei H 2013 Natural killer cells promote immune tolerance by regulating inflammatory $\mathrm{TH} 17$ cells at the human maternal-fetal interface. PNAS 110 E231-E240. (doi:10.1073/ pnas.1206322110) 
Giudice LC 2004 Microarray expression profiling reveals candidate genes for human uterine receptivity. American Journal of Pharmacogenomics 4 299-312. (doi:10.2165/00129785-200404050-00003)

Godkin JD \& Dore JJ 1998 Transforming growth factor $\beta$ and the endometrium. Reviews of Reproduction 3 1-6. (doi:10.1530/ror.0.0030001)

Goetzl EJ, Banda MJ \& Leppert D 1996 Matrix metalloproteinases in immunity. Journal of Immunology 156 1-4.

Gold LI, Saxena B, Mittal KR, Marmor M, Goswami S, Nactigal L, Korc M \& Demopoulos RI 1994 Increased expression of transforming growth factor $\beta$ isoforms and basic fibroblast growth factor in complex hyperplasia and adenocarcinoma of the endometrium: evidence for paracrine and autocrine action. Cancer Research 54 2347-2358.

Gonzalez IT, Barrientos G, Freitag N, Otto T, Thijssen VL, Moschansky P, von Kwiatkowski P, Klapp BF, Winterhager E, Bauersachs S et al. 2012 Uterine NK cells are critical in shaping DC immunogenic functions compatible with pregnancy progression. PLOS ONE 7 e46755. (doi:10. 1371/journal.pone.0046755)

Gutsche S, von Wolff M, Strowitzki T \& Thaler CJ 2003 Seminal plasma induces mRNA expression of IL-1 $\beta$, IL-6 and LIF in endometrial epithelial cells in vitro. Molecular Human Reproduction 9 785-791. (doi:10.1093/ molehr/gag095)

Hatta K, MacLeod RJ, Gerber SA \& Croy BA 2012 Emerging themes in uterine natural killer cell heterogeneity and function. American Journal of Reproductive Immunology 68 282-289. (doi:10.1111/j. 1600-0897.2012.01160.x)

Hemberger M 2013 Immune balance at the foeto-maternal interface as the fulcrum of reproductive success. Journal of Reproductive Immunology 97 36-42. (doi:10.1016/j.jri.2012.10.006)

Higashi K, Inagaki Y, Fujimori K, Nakao A, Kaneko H \& Nakatsuka I 2003 Interferon- $\gamma$ interferes with transforming growth factor- $\beta$ signaling through direct interaction of YB-1 with Smad3. Journal of Biological Chemistry 278 43470-43479. (doi:10.1074/jbc.M302339200)

Johansson M, Bromfield JJ, Jasper MJ \& Robertson SA 2004 Semen activates the female immune response during early pregnancy in mice. Immunology 112 290-300. (doi:10.1111/j.1365-2567.2004.01876.x)

Kaczmarek MM, Krawczynski K, Blitek A, Kiewisz J, Schams D \& Ziecik AJ 2010 Seminal plasma affects prostaglandin synthesis in the porcine oviduct. Theriogenology 74 1207-1220. (doi:10.1016/j.theriogenology. 2010.05.024)

Kaczmarek MM, Krawczynski K \& Filant J 2013 Seminal plasma affects prostaglandin synthesis and angiogenesis in the porcine uterus. Biology of Reproduction 88 72. (doi:10.1095/biolreprod.112.103564)

Kao LC, Tulac S, Lobo S, Imani B, Yang JP, Germeyer A, Osteen K, Taylor RN, Lessey BA \& Giudice LC 2002 Global gene profiling in human endometrium during the window of implantation. Endocrinology 143 2119-2138. (doi:10.1210/endo.143.6.8885)

Kao LC, Germeyer A, Tulac S, Lobo S, Yang JP, Taylor RN, Osteen K, Lessey BA \& Giudice LC 2003 Expression profiling of endometrium from women with endometriosis reveals candidate genes for disease-based implantation failure and infertility. Endocrinology 144 2870-2881. (doi:10.1210/en.2003-0043)

Kawano Y, Matsui N, Kamihigashi S, Narahara H \& Miyakawa I 2000 Effects of interferon- $\gamma$ on secretion of vascular endothelial growth factor by endometrial stromal cells. American Journal of Reproductive Immunology 43 47-52. (doi:10.1111/j.8755-8920.2000.430109.x)

Kryczek I, Frydman N, Gaudin F, Krzysiek R, Fanchin R, Emilie D, Chouaib S, Zou W \& Machelon V 2005 The chemokine SDF-1/CXCL12 contributes to $\mathrm{T}$ lymphocyte recruitment in human pre-ovulatory follicles and coordinates with lymphocytes to increase granulosa cell survival and embryo quality. American Journal of Reproductive Immunology 54 270-283. (doi:10.1111/j.1600-0897.2005.00307.x)

Lee JY, Lee M \& Lee SK 2011 Role of endometrial immune cells in implantation. Clinical and Experimental Reproductive Medicine 38 119-125. (doi:10.5653/cerm.2011.38.3.119)

Lin JX, Migone TS, Tsang M, Friedmann M, Weatherbee JA, Zhou L, Yamauchi A, Bloom ET, Mietz J, John S et al. 1995 The role of shared receptor motifs and common Stat proteins in the generation of cytokine pleiotropy and redundancy by IL-2, IL-4, IL-7, IL-13, and IL-15. Immunity 2 331-339. (doi:10.1016/1074-7613(95)90141-8)

Lovell JW \& Getty R 1968 Fate of semen in the uterus of the sow: histologic study of endometrium during the 27 hours after natural service. American Journal of Veterinary Research 29 609-625.
Male V, Gardner L \& Moffett A 2012 Isolation of cells from the fetomaternal interface. Current Protocols in Immunology Chapter 7 Unit 7 40 41-11. (doi:10.1002/0471142735.im0740s97)

Marbaix E, Kokorine I, Moulin P, Donnez J, Eeckhout Y \& Courtoy PJ 1996 Menstrual breakdown of human endometrium can be mimicked in vitro and is selectively and reversibly blocked by inhibitors of matrix metalloproteinases. PNAS 93 9120-9125. (doi:10.1073/pnas.93.17.9120)

Matsuoka R, Yanaihara A, Saito H, Furusawa Y, Toma Y, Shimizu Y, Yanaihara T \& Okai T 2002 Regulation of estrogen activity in human endometrium: effect of IL-1 $\beta$ on steroid sulfatase activity in human endometrial stromal cells. Steroids 67 655-659. (doi:10.1016/S0039128X(02)00016-8)

McMaster MT, Newton RC, Dey SK \& Andrews GK 1992 Activation and distribution of inflammatory cells in the mouse uterus during the preimplantation period. Journal of Immunology 148 1699-1705.

Meter RA, Wira CR \& Fahey JV 2005 Secretion of monocyte chemotactic protein-1 by human uterine epithelium directs monocyte migration in culture. Fertility and Sterility 84 191-201. (doi:10.1016/j.fertnstert.2005. 01.104)

Moldenhauer LM, Diener KR, Thring DM, Brown MP, Hayball JD \& Robertson SA 2009 Cross-presentation of male seminal fluid antigens elicits $\mathrm{T}$ cell activation to initiate the female immune response to pregnancy. Journal of Immunology 182 8080-8093. (doi:10.4049/ jimmunol.0804018)

Niu N \& Qin X 2013 New insights into IL-7 signaling pathways during early and late $\mathrm{T}$ cell development. Cellular \& Molecular Immunology 10 187-189. (doi:10.1038/cmi.2013.11)

O'Leary S, Jasper MJ, Warnes GM, Armstrong DT \& Robertson SA 2004 Seminal plasma regulates endometrial cytokine expression, leukocyte recruitment and embryo development in the pig. Reproduction 128 237-247. (doi:10.1530/rep.1.00160)

Olive DL, Weinberg JB \& Haney AF 1987 Sperm-macrophage interaction in the mouse: a quantitative assay in vitro using 111 indium oxinelabeled sperm. Biology of Reproduction 37 1170-1178. (doi:10.1095/ biolreprod37.5.1170)

Ooi AT, Ram S, Kuo A, Gilbert JL, Yan W, Pellegrini M, Nickerson DW, Chatila TA \& Gomperts BN 2012 Identification of an interleukin 13-induced epigenetic signature in allergic airway inflammation. American Journal of Translational Research 4 219-228.

Ozaki K \& Leonard WJ 2002 Cytokine and cytokine receptor pleiotropy and redundancy. Journal of Biological Chemistry 277 29355-29358. (doi:10. 1074/jbc.R200003200)

Pandya IJ \& Cohen J 1985 The leukocytic reaction of the human uterine cervix to spermatozoa. Fertility and Sterility 43 417-421.

Politch JA, Tucker L, Bowman FP \& Anderson DJ 2007 Concentrations and significance of cytokines and other immunologic factors in semen of healthy fertile men. Human Reproduction 22 2928-2935. (doi:10.1093/ humrep/dem281)

Pollard JW, Bartocci A, Arceci R, Orlofsky A, Ladner MB \& Stanley ER 1987 Apparent role of the macrophage growth factor, CSF-1, in placental development. Nature 330 484-486. (doi:10.1038/330484a0)

Riesewijk A, Martin J, van Os R, Horcajadas JA, Polman J, Pellicer A, Mosselman S \& Simon C 2003 Gene expression profiling of human endometrial receptivity on days $\mathrm{LH}+2$ versus $\mathrm{LH}+7$ by microarray technology. Molecular Human Reproduction 9 253-264. (doi:10.1093/ molehr/gag037)

Robertson SA 2005 Seminal plasma and male factor signalling in the female reproductive tract. Cell and Tissue Research 322 43-52. (doi:10.1007/ s00441-005-1127-3)

Robertson SA \& Seamark RF 1990 Granulocyte macrophage colony stimulating factor (GM-CSF) in the murine reproductive tract: stimulation by seminal factors. Reproduction, Fertility, and Development 2 359-368. (doi:10.1071/RD9900359)

Robertson SA, Mayrhofer G \& Seamark RF 1992 Uterine epithelial cells synthesize granulocyte-macrophage colony-stimulating factor and interleukin-6 in pregnant and nonpregnant mice. Biology of Reproduction 46 1069-1079. (doi:10.1095/biolreprod46.6.1069)

Robertson SA, Mau VJ, Tremellen KP \& Seamark RF 1996a Role of high molecular weight seminal vesicle proteins in eliciting the uterine inflammatory response to semen in mice. Journal of Reproduction and Fertility 107 265-277. (doi:10.1530/jrf.0.1070265) 
Robertson SA, Mayrhofer G \& Seamark RF 1996b Ovarian steroid hormones regulate granulocyte-macrophage colony-stimulating factor synthesis by uterine epithelial cells in the mouse. Biology of Reproduction 54 183-196. (doi:10.1095/biolreprod54.1.183)

Robertson SA, Guerin LR, Bromfield JJ, Branson KM, Ahlstrom AC \& Care AS 2009 Seminal fluid drives expansion of the $\mathrm{CD} 4{ }^{+} \mathrm{CD} 25^{+}$ $T$ regulatory cell pool and induces tolerance to paternal alloantigens in mice. Biology of Reproduction 80 1036-1045. (doi:10.1095/biolreprod. 108.074658)

Robertson SA, Prins JR, Sharkey DJ \& Moldenhauer LM 2013 Seminal fluid and the generation of regulatory $\mathrm{T}$ cells for embryo implantation. American Journal of Reproductive Immunology 69 315-330. (doi:10. 1111/aji.12107)

Rossi M, Sharkey AM, Vigano P, Fiore G, Furlong R, Florio P, Ambrosini G, Smith SK \& Petraglia F 2005 Identification of genes regulated by interleukin- $1 \beta$ in human endometrial stromal cells. Reproduction $\mathbf{1 3 0}$ 721-729. (doi:10.1530/rep.1.00688)

Rozeboom KJ, Troedsson MH \& Crabo BG 1998 Characterization of uterine leukocyte infiltration in gilts after artificial insemination. Journal of Reproduction and Fertility 114 195-199. (doi:10.1530/jrf.0.1140195)

Rundhaug JE 2005 Matrix metalloproteinases and angiogenesis. Journal of Cellular and Molecular Medicine 9 267-285. (doi:10.1111/j.1582-4934. 2005.tb00355.x)

Salleh N 2014 Diverse roles of prostaglandins in blastocyst implantation. Scientific World Journal 201411.

Sanford TR, De M \& Wood GW 1992 Expression of colony-stimulating factors and inflammatory cytokines in the uterus of CD1 mice during days 1 to 3 of pregnancy. Journal of Reproduction and Fertility 94 213-220. (doi:10.1530/jrf.0.0940213)

Schall TJ, Bacon K, Toy KJ \& Goeddel DV 1990 Selective attraction of monocytes and T lymphocytes of the memory phenotype by cytokine RANTES. Nature 347 669-671. (doi:10.1038/347669a0)

Seymour JF, Lieschke GJ, Grail D, Quilici C, Hodgson G \& Dunn AR 1997 Mice lacking both granulocyte colony-stimulating factor (CSF) and granulocyte-macrophage CSF have impaired reproductive capacity, perturbed neonatal granulopoiesis, lung disease, amyloidosis, and reduced long-term survival. Blood 90 3037-3049.

Sharkey DJ, Tremellen KP, Jasper MJ, Gemzell-Danielsson K \& Robertson SA 2012 Seminal fluid induces leukocyte recruitment and cytokine and chemokine mRNA expression in the human cervix after coitus. Journal of Immunology 188 2445-2454. (doi:10.4049/jimmunol.1102736)

Shima T, Sasaki Y, Itoh M, Nakashima A, Ishii N, Sugamura K \& Saito S 2010 Regulatory T cells are necessary for implantation and maintenance of early pregnancy but not late pregnancy in allogeneic mice. Journal of Reproductive Immunology 85 121-129. (doi:10.1016/j.jri.2010.02.006)

Smith DF, Galkina E, Ley K \& Huo Y 2005 GRO family chemokines are specialized for monocyte arrest from flow. American Journal of Physiology. Heart and Circulatory Physiology 289 H1976-H1984. (doi:10.1152/ajpheart.00153.2005)
Tabibzadeh SS, Satyaswaroop PG \& Rao PN 1988 Antiproliferative effect of interferon- $\gamma$ in human endometrial epithelial cells in vitro: potential local growth modulatory role in endometrium. Journal of Clinical Endocrinology and Metabolism 67 131-138. (doi:10.1210/jcem-67-1-131)

Tafuri A, Alferink J, Moller P, Hammerling GJ \& Arnold B 1995 T cell awareness of paternal alloantigens during pregnancy. Science $\mathbf{2 7 0}$ 630-633. (doi:10.1126/science.270.5236.630)

Tang M, Xu Y, Julian J, Carson D \& Tabibzadeh S 2005 Lefty is expressed in mouse endometrium in estrous cycle and peri-implantation period. Human Reproduction 20 872-880. (doi:10.1093/humrep/deh717)

Taylor NJ 1982 Investigation of sperm-induced cervical leucocytosis by a double mating study in rabbits. Journal of Reproduction and Fertility $\mathbf{6 6}$ 157-160. (doi:10.1530/jrf.0.0660157)

Wadsworth SJ, Atsuta R, Mclntyre JO, Hackett TL, Singhera GK \& Dorscheid DR 2010 IL-13 and TH2 cytokine exposure triggers matrix metalloproteinase 7-mediated Fas ligand cleavage from bronchial epithelial cells. Journal of Allergy and Clinical Immunology 126 366-374, 374 e361-368. . (doi:10.1016/j.jaci.2010.05.015)

Warren JS, Ward PA \& Johnson KJ 1988 Tumor necrosis factor: a plurifunctional mediator of acute inflammation. Modern Pathology 1 242-247

Wood GW, Hausmann E \& Choudhuri R 1997 Relative role of CSF-1, MCP$1 / \mathrm{JE}$, and RANTES in macrophage recruitment during successful pregnancy. Molecular Reproduction and Development 46 62-69; discussion 69-70. (doi:10.1002/(SICI)1098-2795(199701)46:1<62:: AID-MRD10>3.0.CO;2-5)

Wood GW, Hausmann EH \& Kanakaraj K 1999 Expression and regulation of chemokine genes in the mouse uterus during pregnancy. Cytokine 11 1038-1045. (doi:10.1006/cyto.1999.0513)

Yang H, Han S, Kim H, Choi YM, Hwang KJ, Kwo HC, Kim SK \& Cho DJ 2002 Expression of integrins, cyclooxygenases and matrix metalloproteinases in three-dimensional human endometrial cell culture system. Experimental \& Molecular Medicine 34 75-82. (doi:10.1038/emm.2002.11)

Yu Q \& Stamenkovic I 2000 Cell surface-localized matrix metalloproteinase-9 proteolytically activates TGF- $\beta$ and promotes tumor invasion and angiogenesis. Genes and Development 14 163-176.

Yu J, Wei M, Becknell B, Trotta R, Liu S, Boyd Z, Jaung MS, Blaser BW, Sun J, Benson DM Jr et al. 2006 Pro- and antiinflammatory cytokine signaling: reciprocal antagonism regulates interferon $-\gamma$ production by human natural killer cells. Immunity 24 575-590. (doi:10.1016/j. immuni.2006.03.016)

Received 26 February 2015

First decision 26 March 2015

Revised manuscript received 18 May 2015

Accepted 26 May 2015 